\title{
Effects of the Second Language on the First: A Study of ESL Students in China
}

\author{
Xin Wang \\ Henan University, Kaifeng, Henan, China
}

\begin{abstract}
Language transfer may occur in both directions: either from the first language to the second or from the second to the first. The study of language transfer is incomplete if either direction is ignored. Extensive and all-encompassing studies have been witnessed on the study of the effect of the first language on the second while it leaves us much room of investigation related to the study of the effect of the second language on the first. To fill this gap, by virtue of the theory of multi-competence, this study explored the ESL students' transfer of the second language structure to their first language through investigating the effect of English causal clause on the Chinese causal clause. The research found that influenced by the second language knowledge, the middle-level (L2) ESL learners were apt to put the adverbial clause behind the main clause in Chinese, demonstrating that language transfer was bidirectional and there existed backward transfer from the second to the first language. It was also discovered that the transfer was associated with the ESL students' second language proficiency level.
\end{abstract}

Index Terms-multi-competence, English causal clause, Chinese causal clause, backward transfer

\section{INTRODUCTION}

Language transfer plays an indispensable part in the study of second language acquisition. The transfer is bidirectional: the first language can have effect on the second language and the second language can also exert influence on the first language. The former is called forward transfer and the latter backward transfer.

The study of forward transfer has been the interest of linguists and researchers alike for a long time and profound studies have been carried out form various angles: Contrastive Analysis, cross-linguistic influence, resetting of parameters and many others. However, the studies on backward transfer are far from extensive. Laufer, Pavlenko and others have recently conducted relevant researches in multifaceted environments (see Cook, 2003). Also in china, some scholars have begun to pay attention to backward transfer and hence made some insightful observations. Among them are Zhang Jingyue et al. (2006) who studied the influence of English on Chinese by reexamining two "ill-translated sentences" and called it the second language effect in direct translation; Wang Gaiyan (2006) proved the existence of the effect of the second language on the first by using nominal constructions beyond IP as examples; Wu Yi'an et al (2006) made an investigation of the English features in the spoken language of four Chinese speakers of English. Yet there are few studies of the influence of the second language on the first concerning causal clause. Maybe the discrepancies between English and Chinese causal clauses have failed to be noticed by many researchers. The present study, therefore, attempts to prove the existence of backward transfer by investigating the effect of English causal clause on Chinese causal clause.

\section{Multi-competence AND THE SeCOnd LANGUAGe Users}

Cook $(2003$, p. 2) put forward the notion of "mutli-competence" which refers to the "knowledge of two or more languages in one mind". The study of multi-competence is to find out how the two or more languages interact with each other in the mind of a single speaker. The two languages are neither completely isolated nor totally integrated but form an integration continuum. The integration continuum does not necessarily apply to the whole language system. Nor does it necessarily affect individuals in the same way. The integration system may also be connected with different stages of the second language development (Cook, 2003). The second language can affect the first language in at least three ways: it enhances the use of the first language; it harms the use of the first language or it is neutral to the use of the first language.

The second language users are a special group of language users. Their knowledge of the second language is not identical to that of a native speaker; their knowledge of their first language is in some respects not the same as that of a monolingual either. Besides, they have different mind from those of monolinguals (Cook, 2003). So, it stands to reason to claim that ESL students have different minds both from English native speakers and Chinese monolingual speakers in that there are two languages interacting and affecting each other in their minds. As a result, the two linguistic systems may well influence each other. 
Different nations have their own specific thinking pattern due to the differences from the perspective of history, geography, religion, customs and cultural background. Language reflects mind. As far as English and Chinese are concerned, English lays stress on hypotaxis - the use of cohesive devices whereas Chinese on parataxis - the logical relations among the parts. For example, English and Chinese display discrepancies in expressing causal relations. Causal relations play an important role in knowing and understand relations among things. English causal clause and Chinese causal clause are basic ways to show this relation. English and Chinese exhibit some differences as regards the distribution of main and adverbial clauses and whether the connectives can be used together or not.

The connectives of English causal clause include mainly: because, for, since, as, now that, in that. Among them, because is most commonly used. The adverbial clause introduced by because can be placed either before the main clause or after the main clause, manifesting a flexible location. But more often than not, it is placed after the main clause to explain the reason concerned. Besides, because and so are not allowed to be used together.

The connectives exploited in Chinese causal clause are mainly ‘因为', ‘所以’, ‘因为.......所以...... ’ It is generally accepted that Chinese puts emphasis on parataxis, so in many contexts, the causal relations are implied instead of being expressed overtly. The adverbial clause is usually placed before the main clause. Furthermore, the connectives can either be used alone or together. When used together, that is, when '因为.......所以......'is combined, the causal relation it designates is more highlighted and emphasized.

In summary, in English, the unmarked form of the distribution of the causal clause is to put the adverbial clause after the main clause whereas in Chinese, the unmarked form of the distribution of the causal clause is to put the adverbial clause right before the main clause. While it is forbidden to use two connectives in English, it is permitted to use two connectives in Chinese.

\section{Research Design ANd Methodology}

\section{A. Objective and Research Questions}

The purpose of this study is to examine the influence of the second language on the first by way of investigating the effect of knowledge of English causal clause on the use of Chinese causal clause. We try to find whether there exists the backward transfer from English to Chinese for ESL students both in syntax level and in discourse level. There are three research questions as follows:

Question one: As for ESL students, does there exist backward transfer of the knowledge of English causal clause to the use of Chinese causal clause?

Question two: If there is, what is the relationship between the backward transfer and the subjects' second language proficiency level?

Question three: In which type of task do backward transfer occur? And why?

\section{B. Subjects}

Two groups of subjects were selected in the experiment. One group was composed of 40 English majors who, when the experiment was conducted, were in their third year of college in Henan University. Before being enrolled into the university, they had studied English for at least 6 years and after entering the university and majoring in English, they devoted the majority of their time learning English and taking part in activities related to English. Therefore, they could be regarded as second language users. Their English proficiency levels, marked by their TEM4 scores were classified into three kinds: the primary level (L1) was below 65 score, including 12 students, the middle level (L2) was from 66 to 79, including 22 students and the advanced level (L3) was above 80, including 6 students. The other group was monolingual native speakers in Chinese. As it was hard to find 'pure' monolingual speakers who had not studied a second language at all, we decided to choose those who had only learned English in their middle school days. At last, 30 workers from Henan University library were chosen. For this group, they spoke in their mother tongue Chinese and the chance for them to use English in their daily life and at work was next to none.

\section{Methodology and Procedure}

Because there is interaction between syntax and discourse, exclusive focus on either side will lead to incomplete or even contradictory results. In order to probe deeper into the nature of the effect of the second language on the first, we used two different types of tasks as the material in this study. The two types of tasks we used were from Wang Fei (2011). One type of task was taken advantage of to test the subjects' potential transfer from the second language to the first at the syntax level. It was composed of twenty pairs of independent sentences, twelve of which should be connected by causal connectives while the rest eight functioned as the interfering pairs. The twelve pairs were arranged in the opposite order. That is, the adverbial clause in six pairs came before the main sentence of result while the other six pairs were arranged in the opposite order to enable the students to write the sentences in either way. The subjects were required to write causal sentences in adverbial clause - first or main clause - first sequence in their mother tongue Chinese; the other type of task was designed to measure the subjects' transfer from the second language to the first on the discourse level. It consisted of six pictures which were arranged in the temporal order. The subjects were required to write a short story telling what happened to the motorcycle rider. They were told to use at least 3 causal clauses in the whole composition. The experiment was conducted in class at the end of the first term. Time needed to finish the task 
was not limited. After the experiment, the data were collected. In addition, to further testify the results of the experiment, we picked out 20 subjects for interview to get knowledge of their thinking process in the experiment.

\section{Results and Discussion}

Before analyzing the data, the pairs of sentences in the first type of task that were not supposed to be connected by causal connectives would not be counted. The expected twelve pairs linked by causal connectives were picked out and signaled as adverbial clause - first or main clause - first, their frequencies were figured out and their respective percentage in the three levels were gained by dividing the total frequencies at each level. In the same token, the cause-effect complex sentences were selected and marked adverbial clause - first and main clause - first in the discourse level.

To answer the first research question, regarding the ESL students' distribution of Chinese causal clauses, we calculated the percentage of adverbial clause - first and main clause - first at the three levels by Excel. The results and respective figure are presented below in Table 1 and Fig. 1.

TABLE 1

THE PERCENTAGE OF THE ADVERBIAL CLAUSE - FIRST AND MAIN CLAUSE - FIRST AT THE THREE LEVELS

\begin{tabular}{lllll}
\hline Task types & \multicolumn{2}{l}{ The Chinese Syntax Task } & \multicolumn{2}{l}{ The Chinese Discourse Task } \\
\hline $\begin{array}{l}\text { information } \\
\text { sequencing }\end{array}$ & adverbial clause - first & main clause - first & adverbial clause - first & main clause - first \\
\hline L1 & $63.4 \%$ & $36.6 \%$ & 82.7 & 17.3 \\
\hline L2 & $54.2 \%$ & $45.8 \%$ & 75.4 & 24.6 \\
\hline L3 & $76.9 \%$ & $23.1 \%$ & 86.2 & 13.8 \\
\hline
\end{tabular}

Table1 demonstrates that in the Chinese syntax task, in L1 ESL subjects, the frequencies of adverbial clause - first sentences and main clause - first sentences are $63.4 \%$ and $36.6 \%$ respectively; in L2, are $54.2 \%$ and $45.8 \%$ respectively and in L3, are $76.9 \%$ and $23.1 \%$ respectively. It is obvious that in L2, the two frequencies are nearly the same while in the other two levels, there is a big gap in between. It is likely that there exists a certain relationship between the information sequencing and the second language proficiency level of L2 subjects. Besides, we see that in the Chinese discourse level, in L1, the frequencies of adverbial clause - first sentences and main clause - first sentences are $82.7 \%$ and $17.3 \%$ respectively; in L2, are $75.4 \%$ and $24.6 \%$ respectively and in L3, are $86.2 \%$ and $13.8 \%$ respectively. It seems that in the second type of task, the frequency of adverbial clause - first is preferred to main clause - first across three English proficiency levels.

To answer the second research question, finding out the relationship between the information sequencing and the second language proficiency level as well as the third question to find whether the same backward transfer effects are detectable in different types of tasks, we tested the Pearson chi-square using SPSS 18.0. The result is presented in Table 2 below.

TABLE 2

THE RELATIONSHIP BETWEEN ADVERBIAL CLAUSE - FIRST INFORMATION SEQUENCING AND ENGLISH PROFICIENCY LEVELS

\begin{tabular}{llll}
\hline Task types & Chi-square & df & Asymp.sig \\
\hline The Chinese Syntax Task & 6.792 & 2 & .041 \\
\hline The Chinese Discourse Task & 0.946 & 2 & .620 \\
\hline
\end{tabular}

It is noted that $\mathrm{a}=0.05$ means that the possibility of the existence of that relationship is $95 \%$. Table 2 shows to us that in the Chinese syntax task, $\mathrm{P}=0.041$ which is below 0.05 , so the null hypothesis is rejected. In other words, it is demonstrated that there exists relationship between language proficiency levels of the subjects and adverbial clause first sequence in the syntax level; In the Chinese discourse task, $\mathrm{P}=0.620$ which is above 0.05 , so the null hypothesis is accepted. Put it another way, it is shown that there does not exist possible relationship between language proficiency levels of the subjects and adverbial clause - first sequence in the discourse level.

In order to know exactly what kind of relationship there is between the language proficiency level and the adverbial clause - first sequence in the Chinese syntax task, One-Way ANOVA was further tested. The following table shows the result.

TABLE 3

THE RESULT OF ONE-WAY ANOVA

\begin{tabular}{|c|c|c|c|c|c|c|}
\hline \multirow{2}{*}{$\begin{array}{l}\text { (I) } \\
\text { level }\end{array}$} & \multirow{2}{*}{$\begin{array}{l}\text { (J) } \\
\text { level }\end{array}$} & \multirow{2}{*}{$\begin{array}{l}\text { Mean } \\
\text { Difference }\end{array}$} & \multirow{2}{*}{$\begin{array}{l}\text { Std. } \\
\text { Error }\end{array}$} & \multirow[t]{2}{*}{ Sig. } & \multicolumn{2}{|c|}{ 95\%Confidence Interval } \\
\hline & & & & & Lower Bound & Upper Bound \\
\hline \multirow[t]{2}{*}{1} & 2 & $2.1250 *$ & 0.6815 & 0.021 & 0.3055 & 3.9438 \\
\hline & 3 & -1.4129 & 0.8654 & 0.262 & -3.5480 & 0.7086 \\
\hline \multirow[t]{2}{*}{2} & 1 & $-2.1250 *$ & 0.6815 & 0.021 & -3.9438 & -0.3055 \\
\hline & 3 & $-3.1547 *$ & 0.9786 & 0.006 & -5.5615 & -0.7366 \\
\hline \multirow[t]{2}{*}{3} & 1 & 1.4129 & 0.8654 & 0.262 & -0.7086 & 3.5480 \\
\hline & 2 & $3.1547 *$ & 0.9786 & 0.006 & 0.7366 & 5.5615 \\
\hline
\end{tabular}

Table 3 shows that the mean difference between L1 and L2 is 2.1250, 95\% Confidence Interval does not contain 0 , 
Sig. is $0.021<0.05$, showing there is statistical difference between the two levels; the mean difference between L3 and L2 is 3.1547, 95\% Confidence Interval also does not contain 0, Sig. is $0.006<0.05$, showing there is statistical difference between the two levels; the mean difference between L1 and L3 is $-1.4129,95 \%$ Confidence Interval contains 0 , Sig. is $0.262>0.05$, showing there is no statistical difference between the two levels. Therefore, it is concluded that there is the statistical difference between L1 and L 2, L2 and Level 3 but not between L 1 and L 3, meaning that the subjects in L2 perform differently from the other two groups of subjects. To make a comparison with the monolingual native speakers of Chinese, we obtain the following results in Table 4.

TABLE 4

THE PERCENTAGE OF THE ADVERBIAL CLAUSE - FIRST AND MAIN CLAUSE - FIRST IN NATIVE SPEAKERS OF CHINESE

\begin{tabular}{lll}
\hline information sequencing & adverbial clause - first & main clause - first \\
\hline The Chinese Syntax Task & $88.6 \%$ & $11.4 \%$ \\
\hline The Chinese Discourse Task & $95.5 \%$ & $4.5 \%$ \\
\hline
\end{tabular}

From table 4, we can see clearly that the monolingual native speakers of Chinese perform differently from the aforementioned subjects in their preference to put the adverbial clause before the main clause both in the syntax task and in the discourse task. To be specific, in the syntax task, the percentage of adverbial clause - first and main clause first sequence are $88.6 \%$ and $11.4 \%$ respectively while in the discourse task, the percentage of adverbial clause - first is even as high as $95.5 \%$. The result proves once again that the adverbial clause - first sequence is the unmarked distribution in Chinese.

The striking difference between the second group of students and the other two groups in the syntax task calls for explanation. As Neisser (1984) and many scholars have pointed out that backward transfer is not a simple phenomenon that will occur to every individual but is contingent on the second language proficiency level related to a "critical threshold" (Cao Min, 2009). For L2 ESL subjects, their second language proficiency level is below the critical threshold, so they tend to transfer their second language structure to their first. According to Ellis (1985), in order to simplify the learning process and behave like a native speaker, they begin to restructure the linguistic system in their mother tongue or the second language. They act in accordance to the "least effort" principle by replacing their mother tongue structure with the second language structure. For L1 ESL subjects, though their second language proficiency level is also below the threshold level, yet it is unlikely for them to transfer their second language knowledge to their mother tongue because they do not possess enough second language resources to transfer them to their mother tongue. Just as Laufer puts it, at the primary stage of second language learning, the cross-lingual effect is basically unidirectional, namely, from the mother tongue to the second language (Cook, 2003). The second language proficiency level of the L3 ESL subjects is far above the critical threshold and they realize the differences between the information sequencing of the causal clause in the second language and in their mother tongue. Therefore, they are in the position of separating their mother tongue structure from their second language structure and are able to apply them accordingly. That is why when they are performing the two types of tasks, they are not likely to transfer the second language structure to their first language.

There are also some other indications showing the existence of backward transfer both in the syntax task and in the discourse task. First, when some subjects chose the connectives to link the two clauses, they tended to choose one '因 为' or '所以' instead of two '因为......所以......' as the native Chinese speakers did; second, many subjects thought that putting the adverbial clause after the main clause in Chinese was putting the information in focus. As a matter of fact, that is so in their second language structure; and third, many subjects blurred the difference between adverbial clause - first and main clause - first information sequencing. According to them, the two kinds of information sequencing were the nearly the same without any remarkable discrepancy. Last, as said before, Chinese language relies on the coherence among sentences; therefore, it is very common that the cohesive devices will not be used. Nevertheless, it was found that in the discourse task, the number of the ESL subjects who express causal relations without using causal connectives were next to none.

The subjects' different performance in the syntax task and in the discourse task also needs to be analyzed. As noted earlier, the second language effect can be easily detected in the syntax level but not in the discourse level. The interview we conducted after the experiment showed that in the first type of task, the subjects paid more attention to the structure of the sentence and consequently they were apt to transfer the second language unmarked structure to their mother tongue. Some subjects said that they were not even fully aware that they were performing the task in their mother tongue. However, the second task was a coherent whole composed of at least six sentences, so the subjects were more conscious that they were doing the job in their mother tongue.

\section{CONCLUSION}

This paper studied the transfer of the second language to the first through investigating the effect of English causal clause on the Chinese causal clause. The results proved the existence of backward transfer. However, the potential occurrence of backward transfer is not without condition. Backward transfer is closely related to ESL students' second language proficiency level. Only when ESL students' second language proficiency level has not reached a "critical threshold" will they transfer their second language structure to their mother tongue. The second language proficiency 
level of L2 subjects has not reached the "critical threshold", they are thus susceptible to backward transfer. Although the second language proficiency level of L1 subjects is also below the critical threshold, they are unlikely to transfer their mother tongue knowledge to their second language because according to Anderson (1983) they are still in an autonomous, pre-structuring stage (Cao Min, 2009). As for L3 subjects, their English proficiency level is well above the critical threshold and they are able to treat the two language system differently and use them alternately. When the backward transfer occurs, the mother tongue of the ESL students will exhibit some characteristic of their second language. So, contrast to the Chinese native speakers, the L2 subjects tend to put the adverbial clause after the main clause in Chinese causal clause.

The present study, carried out in the mother tongue environment of the second language users confirmed the multi-competence theory advanced by Cook. According to the theory, the multilinguals' linguistic repertoires are a "unified, coherent, interconnected, interdependent system" (Pavlenko, 2003, p. 58). For the subjects in this study, they are second language users of English whose first language is Chinese. The two languages are neither completely separated or combined in their brain. Rather, they are interconnected and interactive. Under this circumstance, it is no doubt that they tend to transfer their second language structure to their mother tongue. However, what should be borne in mind that the main clause - first information sequencing should not be treated as errors because they are only marked forms in the subjects' mother tongue and they can be well accepted by the native speakers. That is why I deliberately avoid using the word attrition here.

The present study is of great significance pedagogically. The emphasis of the second language teaching has always been on the effort to teach students to be native like. As a result, ESL students are usually advised to imitate the native English speakers in language use as well as in thinking pattern. But as Cook (2003) puts it, the second language learners have their own distinctive characteristics: the knowledge of their second language is different from that of a native speakers and the knowledge of their mother tongue is also different from that of a mother tongue monolingual speaker. Due to the fact that the two language systems interact in the single mind of a second language learner, he or she "is a person in his or her own right, not an imitation of someone else" (Cook, 2003, p. 4). Therefore, the objectives of second language teaching or learning are not to encourage the students to imitate the native speakers and pass for them. Rather, teachers should try to get the students to be familiar with the similarities as well as differences between their mother tongue and their second language so as to help them to become owners of multi-competence who can switch between the two language systems flexibly. Besides, ESL students should also improve their mother tongue proficiency level apart from spending most of time improving their second language proficiency level. In this way can they increase the ability of using the second language without losing some of the ability to use their first language.

\section{ACKNOWLEDGEMENT}

This author is indebted to the grant of the following foundation items: Educational and Scientific "the Twelfth Five-Year Plan Project" in Henan Province (project license number: [2011]-JKGHAC-0140*), Teachers' Educational Project in Henan Province (project number: 2013-JSJYYB-007), "the Eleventh Five-Year Plan Project" in Guangdong Province (project number: 09K-03) and the Humanities and Social Sciences Foundation of the Ministry of Education: Applicativizaton and Root Compounding in Mandarin Chinese (project number: 10YJA740044).

\section{REFERENCES}

[1] Cao Min. (2009). The Effect of English Passive Voice Learning on the Use of BEI Sentence by Chinese Freshmen. MA Thesis: Southwest University.

[2] Cook, V (eds). (2003). Effects of the Second Language on the First. Clevedon: Multilingual Matters.

[3] Ellis,R. (1985).Understanding Second Language Acquisition. London: Oxford University Press.

[4] Pavlenko, B. (2003).'I Feel Clumsy Speaking Russian': L2 Influence on L1 in Narratives of Russian L2 Users of English. In Cook, V (eds). Effects of the Second Language on the First (pp.32-61). Clevedon: Multilingual Matters.

[5] Wang Fei. (2011). The Effect of Learning of Order of Information Sequencing in English Adverbial Clauses of Reason on the Use of Chinese Adverbial Clauses of Reason. MA Thesis: Northeast Normal University.

[6] Wang Gaiyan. (2006). Transference from L2 to L1 in Second language Acquisition by Investigating Nominal Constructions beyond IP. Foreign Language Teaching, 27 (5), 40-44.

[7] Wu Yi'an et al. (2006). English Features in the spoken Chinese of Chinese speakers of English. Foreign Language Teaching and Research, 38 (6), 411-417.

[8] Zhang Jingyu et al. (2006). L2 Effect in Direct Translation. Foreign language Literature 2, 113-117.

Xin Wang was born in Henan province in 1981. She received her M A degree in English Linguistic and Literature from Henan University in 2007.

She is now an English lecturer in Foreign Languages Department, Henan University, China. Her research interest is foreign language teaching and cognitive linguistics. 